\title{
Cultura e histerese institucional: a dependência furtadiana como uma instituição histórica
}

Culture and institutional hysteresis: the furtadian dependency as a historical institution

\begin{abstract}
The present article seeks to present an institutional and heterodox analytical framework with which one can study Furtado's cultural dependency concept. Here, an investigation towards the core of the furtadian dependency will be complemented by comments on the institutional dynamics underlying economic relations of production and power. Through the union of these distinct but complementary traditions in economic thought, a long-term model for underdeveloped economic performance will be presented. With such a model, we aim to display how institutionally and culturally dependent economies become locked-in to a given, underdeveloped, pattern of production.
\end{abstract}

\section{Keywords}

cultural dependency, cognitive-institutional hysteresis, long-term economic performance.

JEL Codes B52, O43, P16, O54.

\author{
Marcelo Arend (1) \\ Vinicius Zuniga Fagotti (2) \\ Arthur Gomes Moreira (3) \\ (1) Universidade Federal de Santa Catarina \\ (2) Universidade de Pisa e Escola de Estudos Avançados \\ Sant'Anna \\ (3) University of Sussex
}

\section{Resumo}

O presente artigo busca fornecer uma ferramenta analítica, de cunho institucional e heterodoxo, a ser empregada ao conceito de dependência cultural engenhado por Celso Furtado. Aqui, uma investigação ao cerne da dependência furtadiana será complementada pela apreciação da dinâmica institucional que subjaz as relações econômicas de produção e poder. A partir do casamento dessas distintas e complementares tradições do pensamento econômico um modelo de desempenho de longo prazo para economias subdesenvolvidas, institucional e culturalmente dependentes, será apresentado, formalizando assim o que significa estar aprisionado a um padrão produtivo subdesenvolvido.

\section{Palavras-chave}

dependência cultural, histerese institucional-cognitiva, desempenho econômico de longo prazo.

Códigos JEL B52, O43, P16, O54. 


\section{Introdução}

O objetivo do ensaio é propor uma releitura do conceito de dependência cultural de Celso Furtado, capaz de compreender a condição do subdesenvolvimento numa perspectiva secular. A partir de insights teóricos da literatura neoinstitucionalista evolucionista, procuramos teoricamente institucionalizar o conceito de dependência cultural de Celso Furtado, buscando interpretá-la como um mecanismo de aprisionamento ao subdesenvolvimento. Assim, procuramos enriquecer a leitura de Celso Furtado à luz de novos paradigmas teóricos que ele não conhecia, ou não priorizava em sua época, mas que consideramos compatíveis com sua abordagem.

A teoria de Celso Furtado é elucidativa, excêntrica em sua habilidade de fazer transcender o significado de atraso e subdesenvolvimento; de debilidade tecno-produtiva a debilidade econômica, e de debilidade econômica a dependência cultural e adinamia social. Mas consideramos que ainda fazem-se necessários alguns avanços teóricos. A teoria da dependência cultural que the deu aporte e significado, que gestou o subdesenvolvimento, não elucida efetivamente por meio de quais mecanismos uma economia permanece enviesada e não versa sobre quais fatores operam no sentido de sua materialização e aprisionamento ao subdesenvolvimento. Consideramos que é chegada a hora de institucionalizar a dependência.

Para tal, partiremos das considerações inaugurais de North (1990, 1994), úteis a uma primeira apreciação do que significam as instituições, mas pouco profundas em relação ao nível de desvios à racionalidade econômica que aceitamos em nosso argumento. Pois, mais que guias à ação coordenada entre agentes, as instituições produzem e são produtos do comportamento de seus partícipes; de maneira circular, dinâmica e, indispensável a esse artigo, cumulativa. Aqui, o amálgama institucional à dependência de Furtado estará baseado no que foi proposto por Hodgson (1998), a partir de suas considerações sobre causalidade reconstitutiva; Lane et al. (1996) e Wendt (1992), por meio da exposição dos arranjos cognitivos subjacentes à ação racional; e pelas formulações de histerese e aprisionamento institucionais, trabalhadas por Zysman (1994) e Setterfield (1993), entre outros.

Finalmente, vale ressaltar que, assim como as instituições sociais, o pensamento econômico de Furtado não é nada estático, e grandes cuidados são necessários ao se trabalhar com quase meio século de produção intelectual do demiurgo. Por essa razão, é necessário alertar que esse ar- 
tigo não busca mapear a evolução na teoria furtadiana, ou sugerir que o pensamento de Furtado, como um todo, pode, de maneira homogênea e automática, ser reduzido a considerações de cunho institucionalista. Ao contrário, o que se pretende é mostrar como as linhas mestras da modernização cultural de Furtado, os anseios referentes ao mimetismo suntuoso e à incapacidade coletiva do Brasil subdesenvolvido de crescer sem explorar, ganham contornos mais nítidos ao transpor-se o termo cultural ao arcabouço institucional-cognitivo.

Sendo assim, o presente artigo está estruturado em cinco seções, além desta introdução. Na seção 2 apresentamos uma breve revisão bibliográfica da temática cultura e desenvolvimento e nossa interpretação do conceito de dependência cultural de Celso Furtado, bem como a hipótese de trabalho. Na seção 3 apresentamos nosso conceito original de dependência institucional-cognitiva, considerando a dependência cultural de Furtado a partir do enraizamento histórico de hábitos de comportamento, conforme Hodgson $(1998,2003)$ os concebe, e na ulterior cristalização de uma estrutura institucional específica, notadamente subdesenvolvida, promotora da desigualdade e da heterogeneidade social.

Na seção 4 apresentamos um modelo teórico capaz de diagnosticar como processos de lock-in e de histerese institucional e tecnológica são produzidos em sociedades que sofrem do fenômeno da dependência cultural. Argumentamos que decisões por determinadas estratégias de desenvolvimento de longo prazo sempre são realizadas sob estruturas institucionais (políticas, econômicas e tecnológicas), que incidem sobre os custos relativos de determinada decisão e orientam a ação econômica no curto prazo; derradeiramente, para o caso subdesenvolvido, instigando nos atores econômicos o desejo imediatista pelo consumo emulativo. A reiteração da escolha pelo mimetismo produz mecanismos autorreforçantes e sequenciais, perpetuando o subdesenvolvimento no longo prazo. A seção 5 finaliza o artigo com suas considerações finais.

\section{Cultura, desenvolvimento e dependência: revisão de literatura e construção da hipótese de trabalho}

Segundo Gasper (2006), no discurso dominante a cultura passou a representar a ideia do homo economicus ocidental e o quão distante países subde- 
senvolvidos estão desse prisma. Não é raro encontrar modelos econômicos que presumem que quaisquer pessoas, em quaisquer lugares, estejam sob influência das mesmas percepções e valores. Nessa linha incluem-se economistas da vertente teórica neoclássica e até mesmo os pioneiros da teoria do desenvolvimento, como Rostow e Kuznets, pois abordaram o tema da cultura apenas marginalmente, estudando como instituições, valores e hábitos tradicionais impediam ou promoviam crescimento econômico (Platteau, 2010). Quanto ao desenvolvimento, segundo Gasper (2006), este foi gradualmente deixando de ser entendido como crescimento econômico e passou a incorporar percepções mais amplas sobre o que é considerado relevante diante de escolhas culturais e morais, como apresentado no quadro teórico de Amartya Sen.

Com a ascensão do uso de teoria dos jogos, a relação entre cultura e desenvolvimento se tornou mais sistematizada com a introdução do aspecto cultural como valores que influenciam a decisão de agentes. Essa abordagem permite análises que não requerem uma representação universal do comportamento de indivíduos e que produz modelos microeconômicos sobre comportamentos individuais, inclusive previsões sobre a ação humana (Platteau, 2010).

Um exemplo da abordagem quantitativa é Tabellini (2010), que estuda como a cultura impacta no desenvolvimento econômico em regiões dentro de países europeus. Seu estudo controla efeitos fixos nacionais, taxa de educação atual e de urbanização em 1850 para mensurar como variáveis sobre instituições e alfabetização entre 1600 e 1850 (proxy para cultura) afetam indicadores atuais sobre valores e crenças presentes no World Value Survey para cada região estudada. Regiões historicamente atrasadas (com maior analfabetismo e piores instituições políticas) tendem a ter traços culturais menos favoráveis (menor confiança generalizada, menor respeito ao próximo, menos confiança individual) ao crescimento econômico. Tabellini (2010) indica que o efeito das variáveis históricas no produto regional se dá através da cultura. Portanto, diferenças culturais regionais seriam importantes para explicar como as mesmas instituições formais de todo um território nacional influenciam distintamente seu funcionamento em diferentes regiões. ${ }^{1}$

$1 \mathrm{Na}$ linha de autores, como Tabellini, que atribuem diferenças na qualidade das instituições à cultura, temos Maseland (2013). Em resposta à endogeneidade presente na questão de quem - cultura ou instituições - determina quem, o autor sugere o uso de variáveis biológicas como 
Em contraste com a linha de caráter mais quantitativo apresentada até aqui, algumas das contribuições mais interessantes para a relação entre cultura e desenvolvimento econômico foram dadas por Amartya Sen e Celso Furtado (Amaral Filho; Farias, 2016). Para esses autores, Furtado e Sen ressaltaram como elementos culturais influenciam na trajetória de longo prazo de uma economia em desenvolvimento, distanciando-se do enfoque tradicional que privilegia aspectos quantitativos e microeconômicos. Particularmente na obra de Celso Furtado surge uma abordagem peculiar e distinta dos teóricos do desenvolvimento, pois o autor incorpora explicitamente o tema da cultura na relação com o subdesenvolvimento. Furtado, já na década de 1970, buscou expandir sua própria abordagem econômica ao usar o conceito de cultura, para ir de encontro à incapacidade da disciplina econômica de interpretar a condição do subdesenvolvimento (Cunha; Britto, 2018).

Pode-se defender que Furtado expandiu as ideias de Veblen (1953) para a dinâmica centro-periferia ao argumentar que o consumo pecuniário levou à valorização das ideias e valores das economias centrais, inibindo o florescimento da cultura local. Tais valores culturais estrangeiros foram inseridos, através das elites, no âmbito institucional e econômico das sociedades periféricas. Os elementos estrangeiros acabaram por impedir "conexões sistêmicas" sociais que permitiriam a livre manifestação de identidades culturais originais, necessárias para a construção coletiva do que representa o desenvolvimento. ${ }^{2}$ Ficam marcados assim os dois estigmas das sociedades periféricas que Rodríguez (2009) identificou em Furtado:

proxy exógenas para cultura. Baseando-se em literatura que sugere a ligação de prevalência patogênica com personalidades individuais (que se agregadas representariam uma cultura), o autor se utiliza então do patógeno causador de toxoplasmose, que seria encontrado aleatoriamente tanto em regiões ricas como pobres, e que altera o comportamento humano em nível individual, perpassando para a sociedade, e logo seria fonte de diferenças culturais. As mudanças culturais/em atitudes levariam a diferentes instituições: quando indivíduos infectados passam a apresentar sinais de maior vigilância e menor consciência moral, as pessoas se tornam mais oportunistas e suspeitas das atitudes alheias, reduzindo o nível de confiança de uma sociedade, piorando as instituições e, consequentemente, as atividades econômicas.

2 Furtado (1978) defendeu que a imitação do consumo nos países periféricos veio a impactar muito mais do que variáveis econômicas. Sobre o modo como agem os consumidores, Veblen (1953) informa que, em qualquer comunidade em que bens são tidos como propriedade privada, um indivíduo, para manter um bem-estar emocional, precisa possuir a mesma quantidade de bens que os demais indivíduos de sua classe possuam. Melhor ainda se possuir mais que eles. A emulação garantiria a vontade inerente dos indivíduos a buscar poder de compra para obter tranquilidade de espírito e de mente. O que permitiria obter uma boa reputação seria tal capacidade pecuniária, e o modo de mostrá-la seria através do lazer, do ócio e do consumo conspícuo de bens. 
a heterogeneidade social e a dependência cultural, resultado social da forma com a qual sociedades periféricas se inseriram na lógica da "civilização industrial".

Uma característica marcante do subdesenvolvimento em Furtado, presente nas várias evoluções de seu pensamento, é a preocupação com a proclividade à "desracionalização" das decisões econômicas em sistemas periféricos e dependentes (1974, p. 77-94, 1992, p. 38-48, 2009, p. 160-164). Esse desvio de racionalidade tem caráter cumulativo e forte poder de enraizamento, perdurando à medida que o crescimento do produto permanecer antagônico à homogeneização social. Ou ainda, conforme o estrato modernizado e dependente da sociedade subdesenvolvida demandar bens obteníveis mediante, sobretudo, processos de exploração, em detrimento do progresso técnico (Furtado, 1974, p. 81-82). Ele surge inicialmente por imposição da divisão internacional do trabalho, responsável por delegar ao enclave periférico um tipo regressivo de especialização econômica, que desarticula aumento de produtividade e progresso técnico e extrai o potencial dinamizador do excedente periférico, ${ }^{3}$ e sedimenta-se ulteriormente sob a forma de constrangimentos cognitivos (Furtado chamou-os de culturais).

Dessarte, o impasse original, que seria grosso modo de natureza tecnológica (canaviais/cafezais vs. indústrias), desarticula a economia de tal maneira, e é com tamanho rigor deturpado pela forma de inserção na divisão internacional do trabalho, que faz surgir em economias subdesenvolvidas diferentes tipos de racionalidades econômicas e anseios materiais. $\bigcirc$ que segue é uma espécie de histerese do hábito, que condiciona o subsequente desempenho econômico de determinada sociedade subdesenvolvida.

Dessa relação umbilical e subserviente surge um vínculo suntuoso, de mimetismo econômico, que se fixa no seio do corpo produtor subdesenvolvido. O elevado coeficiente de importações, portanto, reflete um processo muito mais substantivo que agregados, macro ou micro, podem sugerir, porquanto ele é o canal primeiro por onde a economia subdesenvolvida forma laços de identificação com o centro e cria novos hábitos de consumo e preferência, de forma intersubjetiva e cumulativa. À vista disso, o sistema subdesenvolvido passa a importar estilos de vida e valores materiais, inaugurando um "processo de adoção de padrões de consumo sofistica-

3 Afinal, não se pode esquecer que "o desenvolvimento das forças produtivas em condições de dependência não engendra as transformações sociais que estão na base da valorização da força de trabalho" (FURTADO, 1978, p. 60). 
dos (privados e públicos) sem o correspondente processo de acumulação de capital e o progresso nos métodos produtivos" (Furtado, 1974, p. 81), ou simplesmente: modernizando-se. É a partir da modernização que os atores econômicos periféricos perenizam e sancionam seus descompassos entre progresso técnico, acumulação, produtividade e homogeneização social, pois ao pressupor a importação de estilos de vida incompatíveis com o grau de sofisticação produtiva vigente, a modernização subentende esforços econômicos coletivos diferentes daqueles exigidos pelo desenvolvimento econômico. A modernização substitui o progresso e o desenvolvimento enquanto metas, hospedando em seu lugar o desejo mimético de se reproduzir padrões de consumo e se importar prosperidade.

Posto isso, quando uma economia se torna mais complexa em termos de estrutura produtiva, seus laços de dependência e seus processos de modernização mudam de feição, mas não desaparecem. O exemplo histórico a se citar é a industrialização substitutiva de importações. Causado pelo esgotamento estrutural e conjuntural da capacidade importadora de então, o processo de substituição de importações transplantou o mimetismo econômico, que antes se limitava a articulações comerciais, às considerações de investimento e produção da economia, uma vez que o inaugurado elo de realização dos desejos modernizados passou a ser a economia doméstica, e não mais as importações de outrora. Por conseguinte, não obstante a inevitável expansão da renda monetária e do crescimento do produto, o subdesenvolvimento conserva o seu descompasso fundamental no nível de demanda efetiva. De um lado, uma massa desempregada (ou subempregada) inapta a fomentar um mercado homogêneo e de grande envergadura de demanda por bens de consumo populares; de outro, uma minoria modernizada, cuja curva de demanda efetiva fica além da fronteira de produção de sua economia e cujo mimetismo obsessivo perpetua a desigualdade - uma caricatura keynesiana, bifurcada e não complementar. "O distanciamento entre elite e povo será o traço característico do quadro cultural produzido pela modernização dependente. As elites voltam-se, como que hipnotizadas, para os centros da cultura europeia" (Furtado, 2012, p. 38).

Paula (2013) ilustra a necessidade de combater a heterogeneidade social como parte de uma estratégia que Furtado ajudou a construir. Para ele, o desenvolvimentismo furtadiano baseia-se na revolução social brasileira, ou seja, em grandes reformas sociais e estruturais (de reforma agrária ao 
controle do consumo conspícuo) pelas quais garantem-se direitos básicos a todos. $O$ autor defende que na obra furtadiana o programa da revolução social brasileira não é compatível com a dominação burguesa, justamente por se erguer em bases solidárias, de compartilhamento, distribuição de renda, liberdade e protagonismo das classes populares.

Albuquerque (2009) avança na questão da inadequação da tecnologia produzida no centro à dinâmica de acumulação periférica. $\bigcirc$ autor atenta para a repetição do processo de introdução de novos bens de consumo através do consumo imitativo das elites periféricas. Constantes transformações tecnológicas no centro reforçam essa tendência e o resultado é o que o autor chama de polaridade modernização-marginalização - de um lado luxo e gadgets importados, de outro, desemprego estrutural e heterogeneidade social.

Tanto Albuquerque (2009) como Rodríguez (2009), inspirados em Furtado, identificam a necessidade de superar o aprisionamento tecnológico como ponto central na superação do subdesenvolvimento. Mas ao mesmo tempo alertam para a necessidade de uma transformação sociopolítica que rivalize com o arranjo institucional atual, benéfico às elites improdutivas nacionais. Enquanto pela abordagem evolucionária Albuquerque (2009) sugere a construção de sistemas de inovação e de bem-estar social, pela abordagem estruturalista Rodríguez (2009) defende a ideia de desenvolvimento endógeno, que consiste em consolidar a identidade cultural e a criatividade para reverter a dependência cultural.

O que os parágrafos anteriores sugerem transparecer, pautando-se numa análise sensível às diferentes possibilidades de ação econômica (Weber, 2004 [1922], p. 3-16, p. 52-53; Swedberg, 1998, 2005, p. 46-65), é que o capitalismo subdesenvolvido se caracteriza inicialmente por uma defasagem nos meios de produção - ou na tecnologia subjacente à produção -, mas tão logo esse sistema se internacionaliza a pressão exercida pela dependência cultural, fruto da necessidade importadora ligada a essa defasagem na oferta agregada, faz com que a própria racionalidade econômica da sociedade se deturpe. A acumulação culturalmente dependente, sedimentada por reiterados processos de importação e, posteriormente, de identificação com o centro capitalista, não tem como norte a sofisticação produtiva do sistema subdesenvolvido, mas a reprodução material de valores estrangeiros, o simples consumo. É como se a ação socioeconômica obedecesse a uma racionalidade movida a fins completamente entorpecidos, ou "a vida 
como projeto original tende a ser substituída por um processo de adaptação a estímulos exteriores" (Furtado, 1978, p. 76). Como essa racionalidade subdesenvolvida se enraíza nos agentes econômicos, é ela que condiciona o crescimento econômico, e não vice-versa. E uma vez que ela é cumulativa, a cada nova interação econômica dependente ela se reforça, enrijecendo-se em oposição à criação de "conexões sistêmicas" pelo desenvolvimento (Rodríguez, 2009) e se impondo enquanto norma social.

Dito isso, um desafio proposto pelo artigo é explicitar a dinâmica propriamente institucional subjacente à dependência cultural furtadiana. A esse propósito, a recorrência aos ciclos de causalidade constitutiva descendente, conforme proposto por Hodgson (1998), é de grande valia. A partir da lógica inerente à causalidade institucional de Hodgson, um modelo de reforço institucional cognitivo, pautado na relação entre agentes econômicos, seus interesses e capacidades de influência, e a estrutura institucional produtiva, pode ser desenhado. Tal modelo, por sua vez, pode ser analiticamente submetido à passagem do tempo, o que implica dizer que, dados os devidos ajustes conceituais, é possível se esquematizar a relação entre reforço institucional de curto prazo e histerese institucional no longo prazo. Para isso, o modelo de histerese sugerido por Setterfield (1993) fornece um bom ponto de partida. Por conseguinte, a síntese de ambos os modelos, maleada para comportar a dependência cultural, formaliza o argumento teórico neoinstitucional; quer dizer, desvios cognitivos de curto prazo institucionalmente reforçados se tornam desvios de desempenho econômico historicamente aprisionados - e o subdesenvolvimento se perpetua.

Como descrito, a dependência cultural, vista como um fenômeno institucional, influencia a consolidação do subdesenvolvimento em sociedades dependentes, gerando, entre tantas, marginalização e desigualdade. $\mathrm{Na}$ seção seguinte apresentamos um conceito original que permite entender os mecanismos pelos quais tal fenômeno se enraíza no andar histórico de uma economia dependente e subdesenvolvida.

\section{A dependência institucional-cognitiva}

Preliminarmente, cumpre estabelecer o que se entende por instituições, conceito de uso e definição bastante abrangentes. Um primeiro passo importante, em alusão à tradição ortodoxa - a Nova Economia Institucional 
- é reconhecer que em sua acepção mais básica instituições são constrangimentos, restrições e/ou incentivos responsáveis por ordenar ações humanas e por prover uma estrutura interacional mínima por meio da qual expectativas comportamentais possam vir a convergir (North, 1990, 1991, 1994; Williamson, 2000; Young, 1983). Instituições são entendimentos coletivos socialmente aceitos, emanantes da interação repetida entre atores relevantes, que orientam as tomadas de decisões conforme essas ocorram em ambientes complexos e, muitas vezes, carentes de estruturas formais de hierarquia e ordem. Se não funcionam como perfeito corretivo às inescapáveis imprecisões da vida econômica e política, instituições ao menos fornecem um guia à conduta e servem de referência compartilhada ao futuro, o que não é pouca coisa.

Por serem produto da interação humana - e aqui leia-se "da interação entre homens e mulheres", e não entre $n$ atores racionais axiomaticamente condicionados -, instituições são irrevogavelmente dinâmicas, fruto de relações políticas, sociais, culturais e cognitivas; são historicamente determinadas e desenhadas de maneira evolutiva e não automática. Quer dizer, aqui não se desconsidera que não haja racionalidade por trás de arranjos institucionais, apenas que essa racionalidade é condicionada, como já sugeriram Lane et al. (1996). Se entendidas de maneira excessivamente racional, como se produzidas por efeitos similares àqueles da formação de preços em mercados perfeitamente competitivos, as instituições correm o risco de prostrarem-se metodologicamente estéreis. Pois, no limite, não haveria diferença ontológica entre ambos os termos, preço e instituição, no que concerne às suas orientações teleológicas e funcionais (alocação de recursos e tomada de decisões), subordinadas ao funcionamento do mercado. Uma concepção assim estrita não interessa a este trabalho, desde o início ocupado da malformação na racionalidade do homo subdesenvolvidus, com a licença da expressão, algo que não pode ser compreendido sem certo desprendimento de axiomas racionais.

Ao invés disso, se a hipótese inicial é de que a dependência cultural pode ser tida como uma instituição, e se o traço fundamental de dita dependência é seu efeito debilitante sobre a racionalidade própria da sociedade que a hospeda, então é preciso buscar refúgio em formulações mais substantivas do que são instituições. Assim, esse artigo comunga com a vertente de herança vebleniana, costumeiramente denominada de Neoinstitucionalista (Conceição, 2000, 2002). As conceituações basilares dessa 
corrente, enumeradas pontualmente em Samuels (1995), podem ser sintetizadas na seguinte ordem.

Primeiramente, o Neoinstitucionalismo é evolucionista e desconsidera que instituições sejam estáticas ou correspondam a dado estado de equilíbrio; antes, elas respondem às complexidades inerentes ao processo de escolha individual e coletiva, razão pela qual, em segundo lugar, o Neoinstitucionalismo entende que diferentes formas de ação coletiva surgem a partir de diferentes tipos de ordenamentos institucionais, não havendo, ao menos em princípio, alguma primazia necessária do mercado sobre outras formas de organização da produção, dado que todas são variáveis possíveis, dependentes da relação entre agentes e instituições. Em função do exposto, tanto o arcabouço institucional vigente quanto o padrão de produção que ele promove são codeterminados pelo nível tecnológico e pela estrutura de poder em vigor. Os sistemas econômicos compreendem mais que o mercado e, portanto, evoluem de maneira distinta destes.

Por ilação, Samuels (1995) sugere existir algum mecanismo fundamental por meio do qual (1) indivíduos são moldados por instituições, posto que todos nascem dentro de um enquadramento social imposto desde o berço, mas, indispensavelmente, (2) por meio do qual os indivíduos em retorno transformam aquelas instituições iniciais, já que a instituição que se deixa de herança dificilmente é a mesma com a qual se começou. Samuels (1995) cogita caber à cultura esse papel de correia de transmissão e transformação. Em consonância com as apreciações feitas por Hodgson (2003), o presente artigo defende a precedência dos processos e hábitos, dos desenvolvimentos cognitivos subjacentes, enquanto elos dinâmicos entre indivíduo e instituição. E aqui se chega à teoria da dinâmica institucional, indispensável passo para se entender que instituições não são simplesmente sistemas de restrição do comportamento, mas da construção deste. Instituições são sistemas essencialmente cognitivos, responsáveis, claro, pelo constrangimento e direcionamento da ação. Mas elas também transformam os interesses e os atos socialmente vigentes. Elas redefinem os termos pelos quais os agentes se entendem enquanto tais; elas criam novos interesses e novas práticas. ${ }^{4}$

4 Segundo Hodgson (2003, p. 163), "[i]nstitutions both constrain and enable behavior. However, a constrain can open up possibilities: it may enable choices and actions that would otherwise not exist. (...) But a hidden and most pervasive feature of institutions is their capacity to mold and change aspirations, instead of merely enabling them. (...) Because institutions not only depend upon the activities of individuals but also constrain and mold them, 
Dessa forma, instituições se perenizam no comportamento humano por meio do enraizamento de hábitos e concepções coletivos, sendo que o elo entre indivíduo e instituição é função do laço que se estabelece cognitivamente a partir de cada nova interação individual dentro de um determinado marco institucional (Hodgson, 1997; 1998). Isso não significa abandonar pressupostos de racionalidade individual, mas contextualizá-los a partir de concepções substantivas do que significa formar preferências, aprender e, essencialmente, escolher num sistema econômico e social complexo (Lane et al., 1996). Significa aceitar que indivíduos criam hábitos para lidar com a incerteza, e que, além disso, criam sistemas de regras e ordenamentos sociais que reflitam as suas conviç̧ões de identidade - inconscientes inclusive do caráter transformador que essas regras têm sobre aquelas convicções individuais iniciais (Morgan; Olsen, 2010, p. 447-451). ${ }^{5}$

O que requer reconhecer que, em analogia aos estudos de path dependence tecnológica, uma economia também terá sua trajetória institucional marcada por imposições de dependência cumulativa e constrição de aprisionamento, ou lock-ins (Chang; Evans, 2005). Com uma substancial diferença: no caso de aprisionamento institucional, não é tão somente a maneira de se lidar com problemas econômicos que é inescapavelmente condicionada por petrificações institucionais; na verdade, toda a lógica produtiva subjacente - formações de interesses, de preços, de aprendizado, regras e escolhas - é enclausurada pelos ditames institucionais. Assim, as instituições sedimentam os entendimentos de longo prazo de uma economia. O porquê de padrões institucionais de desempenho persistirem pode ser encontrado em Hodgson (1997; 2003; Hodgson; Stoelhorst, 2014) e, novamente, a resposta está ligada às vicissitudes cognitivas e habituais

this positive feedback gives institutions even stronger self-enforcing and self-perpetuating characteristics."

$5 \bigcirc$ resultado cumulativo da repetição institucionalizada de hábitos e práticas, e da sedimentação de interesses correlatos, é o que Zysman (1994) rotula de "trajetórias de crescimento institucionalmente determinadas": "Distinct national paths of economic development and particular technological trajectories are an outgrowth of the institutionally specific context within which each economy operates. The particular historical course of each nation's development creates a political economy with a distinctive institutional structure for governing the markets of labor, land, capital and goods. (...) Predictable patterns of policy and strategy emerge. That is, the institutional structure induces particular kinds of corporate and government behavior by constraining and by laying out a logic to the market and policy-making process that is particular to that political economy. (...) Those national institutions, routines and logics represent adistinct capacity to address particular sets of tasks" (Zysman, 1994, p. 271). 
de um sistema econômico; ao que se denominou de "causalidade reconstitutiva descendente".

A causalidade reconstitutiva descendente é o processo circular mediante o qual instituições definem indivíduos e são por eles definidas, por meio dos hábitos reiteradamente praticados. O que Zysman apresentou de forma descritiva é esboçado de maneira explicativa por Hodgson (2003, p. 167):

As a result, institutions are social structures with the capacity of reconstitutive downward causation, acting upon ingrained habits of thought and action. Powers and constrains associated with institutional structures can encourage changes in thought and behaviour. In turn, upon these repeated acts, new habits of thought and behaviour emerge. It is not simply the individual behaviour that has been changed: there are also changes in habitual dispositions. In turn, these are associated with changed individual understandings, purposes and preferences.

Por esse motivo a noção de hábito é central à teorização de Hodgson (1998). São os hábitos que, mediante suas interações junto a instituições, definem o que cada ator entende ser racional. $O$ processo de causalidade reconstitutiva descendente nada mais é que um termo rebuscado; ele diz respeito pura e simplesmente às interações cumulativas, mediadas pelos hábitos (e expressas por eles), entre indivíduo e instituição; ele é o eixo sobre o qual repousa a dinâmica Neoinstitucionalista, a dinâmica da codeterminação e coevolução institucional. Diferentemente do que se observa na Nova Economia Institucional, o cerne da explicação de Hodgson repousa sobre o significado de determinada configuração institucional, e não sobre sua finalidade. Isso porque o Neoinstitucionalismo não define qual o rumo que certa evolução social deve tomar. Ele apenas explicita o mecanismo por intermédio do qual as forças dessa dada configuração social irão atuar, codeterminando sua trajetória. O fulcro está na interação, não na direção.

É por essa razão, destarte, que o Neoinstitucionalismo responde com tamanho conforto à questão da origem e evolução das instituições. O importante é o processo, não o fim, porquanto sempre haverá uma instituição prévia à ação humana e outra posterior a ela (Hodgson, 1998; Blyth et al., 2011). A precedência ontológica das instituições não repousa na noção de racionalidade, uma vez que não há motivo algum para que se afirme a priori que todas as instituições sejam necessariamente racionais. A precessão institucional é fruto de seu caráter dinâmico, cumulativo, cognitivo e político: o resultado final da interação entre indivíduo e instituição dependerá 
primordialmente da confluência assimétrica e (inclusive) confusa dessas variáveis. O porvir dos arranjos institucionais é sempre aberto.

Mas afinal, seria a dependência furtadiana uma instituição? Em função do exposto até aqui, este artigo sustenta que sim. Conforme se apresentou anteriormente, Furtado já havia estabelecido que a modernização cultural, fruto da condição de dependência, era um hábito enraizado em economias subdesenvolvidas $(1974 ; 1992)$. Que o próprio entendimento coletivo do que significa se desenvolver economicamente, em função da dependência, era enviesado negativamente - propenso ao consumo imediato e ao mimetismo, e que no longo prazo a trajetória econômica dependente seria subordinada à sua capacidade de absorção forçada do excedente (Furtado, 2011 p. 94). A instituição da dependência molda as aspirações de seus indivíduos, suas percepções e seus interesses. Como resultado, a economia opera com uma curva de oferta enviesada (módica): sua autonomia na capacidade de inovar e renovar seu tecido produtivo é pífia. É também refém de uma curva de demanda bivalente, dinâmica em excesso em uma ponta, insuficiente e rudimentar na outra. Sua trajetória cognitiva e institucional a obriga a trilhar um caminho tecnológica e financeiramente servil. Enunciado a partir do léxico da reconstituição descendente causal, os hábitos e entendimentos dependentes foram enraizados e institucionalizados, nas economias subdesenvolvidas em geral e no Brasil em particular, e agora o que se tem são sistemas econômicos aprisionados.

No limite, a instituição que se produz é muito semelhante à hegemonia cultural ideada por Gramsci, ${ }^{6}$ a partir da qual certos grupos sociais são capazes de impor um estilo de desenvolvimento, um bloco histórico, particularmente favorável ao exercício de sua dominação. No entanto, tal configuração institucional hegemônica não pode ser considerada definitiva, porquanto ela ainda se sustenta sobre bases dinâmicas e intersubjetivamente construídas. Seria contraditório, à luz desta seção, considerá-las de maneira determinística e/ou fechada.

A operacionalização teórica de sucessivas rodadas de modernização e atualização de padrões de consumo é apresentada na próxima seção. Mostramos como distintas estratégias de desenvolvimento perpetuam a condição do subdesenvolvimento nacional no longo prazo, num modelo de histerese e aprisionamento institucional. narrativas na economia política brasileira, uma boa incursão preliminar está em Grün (2011). 


\section{Fechamento do modelo institucional-cognitivo de dependência cultural: histerese e aprisionamento à condição do subdesenvolvimento}

Quanto mais antiga é uma instituição, mais rígida e inelástica à ação marginal de seus agentes ela é (Setterfield, 1993); também: mais ela é tida como um fato social imutável, e mais os agentes se identificam e formam preferências em termos estritamente ligados a essa determinada instituição (Dugger, 1988; Wendt, 1992). Quer dizer que os agentes não conseguem escolher e agir economicamente em dissonância com o padrão de comportamento institucionalmente enraizado; muito em semelhança ao que Lane et al. (1996) argumentam, quando falam de relacionamentos generativos, e semelhante também ao estudo de Morgan e Olsen (2010) referente à construção e sedimentação de regras de conduta institucionalmente gestadas. Com efeito: os agentes não conseguem internalizar rotinas de produção, não conseguem formar curvas de demanda por investimento, são incapazes de conceber variações na composição e distribuição de renda, que não advenham do padrão produtivo que se enraíza (Zysman, 1994).

A maleabilidade institucional de longo prazo é inversamente proporcional à ideia de idade institucional. Arranjos institucionais mais incipientes são menos definidos; são ordenamentos em construção, e por emanarem da ação humana, são mais suscetíveis em sua infância (Grün, 2011; Torfing, 1999). Porém, conforme instituições se avolumam em termos de ações padronizadas acumuladas, elas progressivamente passam a ser a fonte de referência para a ação humana subsequente (North, 1990, 1994); elas se tornam o modelo a partir do qual os agentes aprendem a formar suas preferências e, com efeito, se tornam as estruturas a partir das quais as escolhas econômicas são tomadas (Hodgson, 1998). Isso não significa que os agentes não possam jamais alterar suas instituições sedimentadas - o que seria um contrassenso, já que instituições são formadas por ações humanas. Em vez disso, ocorre que a mera possibilidade de modificação institucional é cada vez menos perceptível aos agentes econômicos (Wendt, 1992). Além do mais, a eles uma mudança não necessariamente seria favorável, porquanto estruturas institucionais também são fontes de identidades. A rigor: agentes econômicos se identificam com suas instituições econômicas e com a estabilidade com que elas os provêm (Ruggie, 1983; Fligstein, 2001), sem mencionar que existem altos custos econômicos implícitos às alterações 
requeridas para a sublevação de um arcabouço institucional (Tool, 1977), e que, como Keynes (1996 [1936]) logrou demonstrar, o véu da incerteza é um peso conservador no tangente a ações econômicas.

A esse fenômeno de aprisionamento particular às instituições convém chamar de histerese institucional (Setterfield, 1993; Bueno, 1996); no caso que importa a este artigo, o aprisionamento é parte da razão porque agentes econômicos não conseguem sequer conceber a possibilidade de emancipação da dependência cultural.

A condição do subdesenvolvimento, portanto, é ubíqua porque a histerese institucional germina, como se buscou explicitar, trajetórias econômicas progressivamente enrijecidas. Em outras palavras, assim como a reiteração cumulativa de ações e escolhas forma instituições, a reiteração de sistemas institucionais no tempo produz trajetórias econômicas específicas, sejam elas eficientes ou não. Assim, feito um equilibrista circense, a economia tende a marchar de acordo com as possibilidades auferidas pela linha mestra que é a sua trajetória econômica. Claro que existem possibilidades além da linha de equilíbrio, mas o condicionamento institucional negativo é precisamente isso: a impossibilidade dos agentes de entenderem suas possibilidades econômicas sem se referir à alegoria do funambulismo. A Figura 1, a seguir, ilustra o que se apresentou até aqui.

Figura 1 Formação de trajetórias institucionais e desempenho econômico

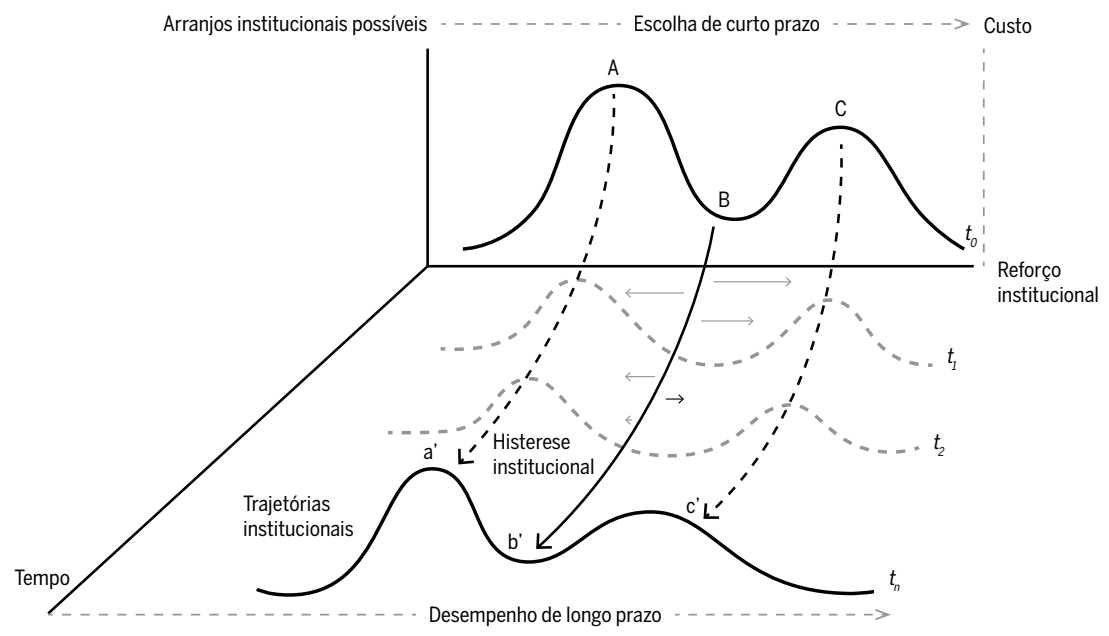

Fonte: Elaboração própria. Ver, também, Setterfield (1993, p. 768). 
O que a figura pretende apresentar é que, no curto prazo, uma economia conta com um conjunto de alternativas institucionais à disposição, e que a proclividade geral dos agentes econômicos tende a se dar em favor daquele ordenamento institucional que, por representar a estrutura socialmente mais aceita e difundida, afere a determinada escolha os menores custos imediatos. No caso em questão, pensamos em distintos arranjos institucionais, referentes a distintas estratégias de desenvolvimento, e suas estruturas de custos no concernente à atualização de padrões de consumo estrangeiros em determinada conjuntura. Essa configuração de custos pode ser entendida a partir de um viés microeconômico, mas o essencial é não perder de vista a influência que a causalidade reconstitutiva e o reforço institucional exercem sobre como os agentes entendem, aprendem, se identificam e formam preferências em sociedade.

A rigor, significa, pois, que a estrutura de custo em si também é institucionalmente condicionada, posto que o processo de reforço e coevolução institucional age no sentido de ordenar o processo de escolha a partir de parâmetros institucionalmente fornecidos. De forma mais rudimentarmente dita, as escolhas mais baratas são as mais seguras, acessíveis, e socialmente aceitas, por isso apresentam custos menores, e essas qualidades mencionadas existem porque um arcabouço institucional trata de reposicionar os custos relativos das escolhas econômicas. Conforme já foi dito, escolhas afetam instituições, mas essas são tomadas dentro de um ordenamento criado por aquelas.

Por não ocorrer no vácuo, a dinâmica de escolha institucional é também temporalmente condicionada. Destarte, as escolhas econômicas ocorrem no tempo to, mas tão logo elas se dão o tempo cronológico impõe mais uma rodada de escolhas conforme o padrão de consumo necessita ser atualizado, em t1, e assim sucessivamente, até o curto prazo ter se sedimentado em uma longa trajetória, $t n$, de codeterminação institucional-cognitiva. $\bigcirc$ que se deve depreender da Figura 1 é que, quanto mais próximas de $t 0$, mais institucionalmente fluidas podem ser as escolhas dos agentes econômicos; em outras palavras, menor é o hiato de custos entre um ordenamento institucional e outro, e maiores as chances de mudanças e alterações, tanto para outras configurações institucionais, quanto para dentro das possibilidades previstas pela configuração institucional em vigência.

reforço institucional é, enfim, amplificado pela cumulatividade temporal das ações e escolhas individuais dos atores econômicos, o que pro- 
gressivamente encarece e inviabiliza as alternativas institucionais presentes em to ou t1. No limite, a economia se encontrará em histerese; ela estará cognitivamente aprisionada aos padrões de comportamento construídos no passado e, fundamentalmente, estará presa a um viés extremamente rígido de desempenho futuro para o longo prazo.

De acordo com a Figura 1, trajetórias institucionais são criadas quando pontos iniciais, como A, B ou C, se deslocam temporalmente e culminam em a', b' ou c'. Implicando dizer, por conseguinte, que aqui se sugere uma importante relação entre escolhas estáticas de curto prazo e desempenhos dinâmicos no longo prazo. Precipuamente, um importante ponto de tensão surge quando se considera que as escolhas de curto prazo são avaliadas e avalizadas a partir de parâmetros diferentes (custos) daqueles que determinam qual trajetória de longo prazo é a mais profícua para uma economia (eficiência schumpeteriana ou complexidade). Conceitualmente, isso significa que, em função de condicionamentos institucionais e cognitivos, decisões tidas como corretas podem levar, no longo prazo, a ineficiências e baixa produtividade duradouras, reforçadas e perpetuadas pela histerese que se instaura. É nessa contradição que acreditamos se encontrar parte da resposta do porquê da ubiquidade da dependência cultural; condição que é institucional, cognitiva e evolucionária.

A dependência cultural é uma instituição histórica porque ela paira sobre as principais mudanças institucionais que a sociedade brasileira passou no último século. Portanto, ela pode ser entendida como uma instituição pétrea da condição do subdesenvolvimento. No capitalismo agroexportador do final do século XIX ao inicio do século XX, as elites nacionais satisfaziam seu padrão de consumo através da clássica configuração centro-periferia, exportando produtos agrícolas para garantir importações de bens de consumo ingleses e franceses frutos da revolução industrial europeia, mantendo praticamente três quartos da sociedade brasileira em situação de economia de subsistência. Durante o processo de industrialização, o estado desenvolvimentista em associação com o capital estrangeiro e as elites nacionais avançou na internalização de um parque produtivo capaz de atender a demanda insatisfeita de classe média alta, imitativa de sociedades com nível de acumulação mais avançado, em razão do persistente estrangulamento externo. Essa escolha, marcada pelo menor custo de curto prazo para atualização do padrão de consumo da elite brasileira pode ser entendido optando-se pelo arranjo institucional B da Figura 1. 
É praticamente consenso na historiografia econômica que a industrialização pesada do Brasil optou pela internacionalização do mercado, com o ingresso de multinacionais em setores e atividades produtivas de bens de consumo duráveis. Essa estratégia provou rápida internalização de tecnologias avançadas, porém suplantou a trajetória inicialmente mais custosa e temporalmente mais autônoma, que requeria aprendizado tecnológico local, relativa a investimentos em ativos baseados em conhecimento. $O$ ritmo da industrialização dependente seguiu o esforço para adaptar as técnicas do Norte Global. Entretanto, no Sul, houve um descompasso com a orquestração dos conflitos sociopolíticos do Norte, obra propulsora das transformações estruturais e sociais por lá mais ressonantes, informa Furtado (1978). Assim, o novo padrão de acumulação (opção B, menos custosa no curto prazo) internalizou as tecnologias típicas da revolução fordista norte-americana. Entre as décadas de 1950 e 1970, os "50 anos em 5" do governo JK e o "milagre econômico" do regime militar avançaram na industrialização brasileira, porém esse catching-up produtivo às economias centrais ocorreu com a exacerbação da dependência tecnológica e financeira, e com elevação da desigualdade social, rebaixamento dos salários reais, autoritarismo e torturas.

$\mathrm{O}$ atraso tecno-produtivo que passou a vigorar em território nacional desde os anos 1980, marcado pelo processo de desindustrialização precoce, não impediu um novo processo de modernização do padrão de consumo das elites nacionais na década de 1990, em função de uma nova revolução tecnológica nos países centrais, ancorada na microeletrônica e nas telecomunicações. O Brasil, industrializado mas sem ter aprendizado tecnológico, aprisionado pela escolha $\mathrm{B}$, em sua ânsia de atualizar o consumo de fração de sua população, aprofundou em $t 1$ a abertura comercial, realizou privatizações, praticou câmbio valorizado e juros elevados; foram mecanismos de mudança institucional arquitetados para a preservação da instituição pétrea do subdesenvolvimento, possibilitando crescimento explosivo das importações de bens de consumo modernos, das viagens internacionais e do rentismo à elite modernizada. No final da segunda década do século XXI a sociedade brasileira optou novamente pela escolha de $\mathrm{B}$, em $t 2$, e uma nova rodada de mudanças institucionais assegurará a atualização do padrão de consumo elitizado na iminência de uma nova revolução industrial, a indústria 4.0. Flexibilização das leis trabalhistas, reforma previdenciária, limite para gastos públicos e até mesmo degradação 
do meio ambiente são mudanças institucionais que prometem um novo "milagre econômico", numa nova rodada de modernização com marginalização. A economia brasileira possivelmente continuará sendo uma das dez mais ricas do planeta, apesar de continuar a ser uma das mais desiguais. A questão fundamental da análise é compreender, como procuramos detalhar teoricamente, que certas escolhas institucionais de curto prazo, que $a$ priori possuem custos menores e prometem benefícios elevados no longo prazo (50 anos em 5, milagre econômico, neoliberalismo), cobram seu preço no futuro. Se a trajetória institucional de longo prazo não desenvolveu "ativos baseados em conhecimento", não há por que visualizar num futuro distante novos milagres econômicos. O Brasil no limiar da terceira década do século XXI, em plena histerese institucional-cognitiva e atraso tecnológico, vislumbra um novo "milagre" curto-prazista a partir de uma nova rodada de internacionalização de sua economia, como forma de incitar novamente a mudança estrutural. Como nos anos de 1950, 1970 e 1990, não contabilizando os custos futuros por abdicar da construção de seus próprios ativos baseados em conhecimento. Porém, garantindo a atualização e modernização do padrão de consumo de sua elite.

Uma vez pregressas as várias rodadas de interações econômicas negativamente enviesadas, o caráter cumulativo e circular das instituições se ocupa de normalizar tal desvio de racionalidade (Hodgson, 1998, 2003; Chang; Evans, 2005). Conforme mostramos na seção 2, esse argumento é muito similar ao que propôs Celso Furtado para o caso da industrialização do Brasil no século XX (2011, p. 171-195,7 1977, p. 192-195). A chamada dependência cultural, sob a égide furtadiana, é uma deficiência que deturpa as curvas de demanda efetiva de um país, incapacitando-o de crescer de maneira "independente", equânime e sustentável (Furtado, 1977, p. 88). Segundo essa lógica, a constante incorporação de tecnologia adaptada do exterior, para seu fim último que é a modernização de padrões de consumo, em vez de internalizar os centros de decisão e o progresso técnico nacional, produz exatamente o contrário: a internacionalização dos centros de decisão, tornando o país inabilitado de criar um mercado interno sofisticado com homogeneidade social (Furtado, 1992, p. 44), além de

7 Ver também, em Raízes do subdesenvolvimento (2011), as considerações sobre a não neutralidade do progresso técnico, presentes a partir da página 96. Adiante, a leitura do capítulo terceiro de $O$ mito do desenvolvimento econômico (1974), intitulado "O modelo brasileiro de subdesenvolvimento", sintetiza muito do que foi abordado até agora. 
prescindir da construção de capitais nacionais com vantagens competitivas sobre bens tecnologicamente dinâmicos (Furtado, 2011, p. 206-209). O efeito ulterior é a criação de uma economia amplamente dependente de mercados exteriores e marcada pela ampliação da heterogeneidade social, da exploração salarial como contrapeso à ineficiência tecnológica (Furtado, 2009, p. 158-159). Uma situação tal qual a descrita é muito mais fácil de ser concebida se se admitem desvios institucionais e cognitivos, acumulados e reforçados com o passar do tempo, sedimentados nos agentes econômicos (Zysman, 1994; Hodgson, 2003).

Adaptando o roteiro ao léxico propriamente evolucionário, significa, portanto, que um dado padrão tecnológico e uma dada capacidade de produção reforçam, e são reforçados, pelas instituições em que se encontram e pelos agentes econômicos que nela atuam (Zysman, 1994). Por conseguinte, as potencialidades de uma economia são determinadas por suas estruturas tecnológicas e, derradeiramente, por como seus agentes econômicos interagem com essa estrutura. Esse fenômeno de interação, de formação de preferências, escolhas e tomadas de ação, se dá sempre em reflexo, cumulativo e circular, às instituições econômicas e sociais (Conceição, 2002, 2008; Samuels, 1995).

As inovações institucionais incorporadas em sociedades dependentes tendem a ser mais um caso de mimetismo ideológico do que de consenso derivado de autêntica criatividade política (Furtado, 1978, p. 82). Valores como nacionalismo, defesa da família e civilização cristã são utilizados com frequência sazonal, incluso em voga nesta passagem de década, como "superideologias de função essencialmente moderadora", como identificou Furtado (1978), para barrar o tão necessário pluralismo institucional na periferia e conter contestações contra interesses da elite. E a instituição inveterada do subdesenvolvimento resiste intocada.

Celso Furtado, em sua obra intitulada Criatividade e dependência na civilização industrial, já no final da década de 1970, possibilita ricos insights para refletirmos sobre a atual armadilha institucional em que se encontra a economia brasileira no limiar do século XXI. Furtado (1978), questionando-se sobre a possibilidade da superação da dependência numa economia global dominada por grandes capitais transnacionais, não vislumbra uma superação da condição do subdesenvolvimento pela via do isolacionismo. "Para a quase totalidade dos países periféricos, já não existe a possibilidade de escapar ao campo gravitacional da civilização industrial; portanto, é 
no quadro desta que se dará a luta contra a dependência" (Furtado, 1978, p. 103). A estratégia de superação da dependência passaria pelo maior controle do principal recurso de poder das relações econômicas internacionais: a tecnologia. Se a tecnologia é o recurso singular do conjunto e aquele que é monopolizado pelos países centrais, então "a dependência é primeiramente tecnológica. Reunir outros recursos de poder para neutralizar ainda que parcialmente o peso da dependência tecnológica - eis a essência do esforço que realizam os países periféricos para avançar pela via do desenvolvimento" (Furtado, 1978, p. 111). Como o controle da tecnologia na civilização industrial é possibilitado pela criatividade, somente com a arrasadura da dependência cultural dos modelos mentais cognitivos da elite brasileira seria possível tal acesso ao principal recurso de poder. Seria, portanto, necessário não mais acessar indiretamente, na forma de transferências tecnológicas, os frutos da civilização industrial, mas construí-los. Desafortunadamente, a condição do subdesenvolvimento é de fato tão ubíqua porque ela é uma armadilha não apenas sob o ponto de vista tecnológico, mas também comportamental e cognitivo. E, portanto, institucional.

\section{Considerações finais}

A hipótese norteadora do artigo é a de que a dependência cultural é uma instituição histórica. Ela é uma forma de se entender a persistência de hegemonias políticas e econômicas, surgidas a partir de diversas interações entre agentes subordinados e dominantes, responsáveis por produzir um histórico hábito social de desejo mimético, hodiernamente mais do que nunca enraizado no seio da sociedade brasileira. Essa dependência, que intitulamos de institucional-cognitiva, logrou subordinar decisivamente a trajetória econômica do Brasil, tornando-a subdesenvolvida. As várias fases dessa trajetória gestaram diferentes tipos de capitalismos brasileiros: alguns mais propensos ao crescimento, como durante o processo de industrialização do regime militar, outros menos, imersos em conjunturas estagnacionistas e marcados por desindustrialização, financeirização e reprimarização produtiva; todos eles subdesenvolvidos e presos à sedimentação histórico-institucional da dependência.

No constructo furtadiano, uma economia subdesenvolvida é cronicamente incapaz de liderar revoluções schumpeterianas tecnológicas 
mundiais, e a cada nova onda de desenvolvimento global se vê coagida e distanciada daquilo que pretende imitar. Por isso, a instituição pétrea (dependência cultural) permite rearranjos institucionais incrementais nas regras do jogo ao longo do tempo, mas não mais que isso. Pensando na economia brasileira do século XXI, quando a exploração por si só não basta, o mimetismo perdulário deve ser financiado por outros meios: o atraso da estrutura produtiva leva às importações, que se somam ao endividamento público, à introdução de multinacionais no tecido econômico e ao crescimento com poupança externa, indiferentemente a crises de liquidez ou solvência. Permitindo-se uma digressão em economia política internacional, o estágio mais avançado do subdesenvolvimento é aquele em que o mimetismo perdulário é pago com alienação do poder econômico (Furtado, 2011, p. 206-209).

\section{Referências}

ALBUQUERQUE, E. Catching up no século XXI: construção combinada de sistemas de inovação e de bem-estar social, in: SICSÚ, J.; MIRANDA, P. (Ed.). Crescimento econômico: estratégias e instituições. Rio de Janeiro: IPEA, 2009. pp. 55-84.

AMARAL FILHO, J. do; FARIAS, D. B. L. Celso Furtado: Culture and Creativity Matter. Journal of Economic Issues, v. 50, 444-451, 2016.

BLYTH, M.; HODGON, G.; LEWIS, O.; STEINMO, S. Introduction to the Special Issue on the Evolution of Institutions. Journal of Institutional Economics, v. 7, n. 3, p. 299-315, 19 May, 2011. Cambridge University Press (CUP).

BUENO, N. P. Um modelo de histerese institucional para a análise da política industrial brasileira. Pesquisa e Planejamento Econômico, Rio de Janeiro, v. 26, n. 2, p. 333-348, jul. 1996.

CHANG, H. J.; EVANS, P. The Role of Institutions in Economic Change. In: PAULA, S. de; DIMSKY, G. A. (Ed.). Reimagining growth: towards a renewal of Development Theory. Chicago: Chicago University Press, 2005. p. 99-129.

CONCEIÇÃO, O. A. C. Os antigos, os novos e os neoinstitucionalistas: há convergência teórica no pensamento institucionalista? Análise Econômica, Porto Alegre, v. 33, n. 18, p. 25-45, mar. 2000.

CONCEIÇÃO, O. A. C. O conceito de instituição nas abordagens institucionalistas. Revista de Economia Contemporânea, Rio de Janeiro, v. 6, n. 2, p. 119-146, dez. 2002.

CONCEIÇÃO, O. A. C. A dimensão institucional do processo de crescimento econômico: inovações e mudanças institucionais, rotinas e tecnologia social. Economia e Sociedade, Campinas, v. 17, n. 1, p. 85-105, abr. 2008.

CUNHA, A. M.; BRITTO, G. When development meets culture: the contribution of Celso Furtado in the 1970s. Cambridge Journal of Economy, v. 42, n. 1, p. 177-198, jan. 2018. 
DUGGER, W. M. Radical institutionalism: basic concepts. Review of Radical Political Economics, v. 20, n. 1, p. 1-20, 1 mar. 1988.

FLIGSTEIN, N. Mercado como política: uma abordagem político-cultural das instituições de mercado. Contemporaneidade e Educação, Rio de Janeiro, v. 7, n. 9, p. 26-55, set. 2001.

FURTADO, C. O mito do desenvolvimento econômico. Rio de Janeiro: Paz e Terra, 1974.

FURTADO, C. Prefácio à nova economia política. Rio de Janeiro: Paz e Terra, 1976.

FURTADO, C. Teoria e política do desenvolvimento econômico. 6. ed. São Paulo: Editora Nacional, 1977.

FURTADO, C. Criatividade e dependência na civilização industrial. Paz e Terra, 1978.

FURTADO, C. Brasil: a construção interrompida. 3. ed. Rio de Janeiro: Paz e Terra, 1992.

FURTADO, C. Desenvolvimento e subdesenvolvimento. Apresentação: Rosa Freire d'Aguiar Furtado. 5. ed. Rio de Janeiro: Centro Internacional Celso Furtado, Contraponto, 2009 [1961].

FURTADO, C. Raízes do subdesenvolvimento. 2. ed. Rio de Janeiro: Civilização Brasileira, 2011 [2003].

FURTADO, C. Ensaios sobre a cultura e o Ministério da Cultura. D'AGUIAR, R. F. (Org.). Rio de Janeiro: Contraponto, Centro Internacional Celso Furtado, 2012.

GASPER, D. Culture and Development. In: Clark, D. A. (Ed.). The Elgar Companion to Development Studies. Edward Elgar, UK, 2006. pp. 96-101.

GRÜN, R. Crise Financeira 2.0: controlar a narrativa e controlar o desfecho. Revista de Ciências Sociais, Rio de Janeiro, v. 54, n. 3, p. 307-354, mar. 2001.

HODGSON, G. M. The ubiquity of habits and rules. Cambridge Journal Economics, Cambridge, v. 21, n. 6, p. 663-684, mar. 1997.

HODGSON, G. M. The Approach of Institutional Economics. Journal of Economic Literature, Nashville, v. 36, n. 1, p. 166-192, mar. 1998.

HODGSON, G. M. The hidden persuaders: institutions and individuals in economic theory. Cambridge Journal of Economics, Cambridge, v. 27, n. 2, p. 159-175, mar. 2003.

HODGSON, G. M.; STOELHORST, J. W. Introduction to the special issue on the future of institutional and evolutionary economics. Journal of Institutional Economics, v. 10, n. 4, p. 513-540, 26 ago. 2014.

KEYNES, J. M. A teoria geral do emprego, juro e da moeda. São Paulo: Nova Cultural, 1996 [1936].

LANE, D.; MALERBA, F.; MAXFIELD, R.; ORSENIGO, L. Choice and action. Journal of Evolutionary Economics, Berlim, v. 6, n. 1, p. 43-76, abr. 1996.

MORGAN, J.; OLSEN, W. Conceptual issues in institutional economics: clarifying the fluidity of rules. Journal of Institutional Economics, v. 7, n. 3, p. 425-454, 27 ago. 2010. Cambridge University Press (CUP).

NORTH, D. C. Institutions, institutional change and economic performance. Cambridge, UK: Cambridge University Press, 1990.

NORTH, D. C. Institutions. The Journal of Economic Perspectives, Nashville, v. 5, n. 1, p. 97-112, jul. 1991.

NORTH, D. C. Economic performance through time. The American Economic Review, Nash- 
ville, v. 84, n. 3, p. 359-368, jun. 1994.

PAULA, J. A. Celso Furtado, desenvolvimento e transformação social, in: d'Aguiar, R.F. (Ed.). Celso Furtado e dimensão cultural do desenvolvimento. , Rio de Janeiro: Centro Internacional Celso Furtado, 2013. pp. 13-48. Coleção Pensamento Crítico.

PLATTEAU, J.-P. The role of culture in development, in: PLATTEAU, J.-P.; PECCOUD, R. (Ed.). Culture, Institutions, and Development: New Insights Into an Old Debate. Routledge, 2010. pp. 3-19.

RODRÍGUEZ, O. Desenvolvimento e cultura: a perspectiva de Celso Furtado, in: Rodríguez, O. (Ed.). O estruturalismo latino-americano. Rio de Janeiro: Civilização Brasileira: Cepal, 2009. pp. 405-448.

RUGGIE, J. G. International regimes, transactions, and change: embedded liberalism in the postwar economic order. In: KRASNER, S. International regimes. Ithaca: Cornell University Press, 1983. p. 195-231.

SAMUELS, W. J. The present state of institutional economics. Cambridge Journal of Economics, Cambridge, v. 19, n. 4, p. 569-590, 1995.

SETTERFIELD, M. A model of institutional hysteresis. Journal of Economic Issues, Abingdon, v. 27 , n. 3, p. $755-774$, set. 1993 .

TABELLINI, G. Culture and Institutions: Economic Development in the Regions of Europe. Journal of the European Economic Association, v. 8, n. 4, p. 677-716, 1 jun. 2010.

TOOL, M. A social value theory in neoinstitutional economics. Journal of Economic Issues, Abingdon, v. 11, n. 4, p. 823-846, dez. 1977.

TORFING, J. Towards a Schumpeterian workfare postnational regime: path-shaping and path-dependency in Danish welfare state reform. Economy and Society, v. 28, n. 3, p. 369402, ago. 1999.

VEBLEN, T. The Theory of the Leisure Class: An Economic Study of Institutions. New American Library, 1953.

WEBER, M. Economia e sociedade: fundamentos da sociologia compreensiva. Brasília: Universidade de Brasília, 2004 [1923].

WENDT, A. Anarchy is what states make of it: the social construction of power politics. International Organization, Cambridge, v. 46, n. 2, p. 391-425, abr. 1992.

WILLIAMSON, O. E. The New Institutional Economics: Taking Stock, Looking Ahead. Journal of Economic Literature, Nashville, v. 38, n. 3, p. 595-613, set. 2000.

YOUNG, O. R. Regime dynamics: the rise and fall of international regimes. In: KRASNER, Stephen (Ed.). International Regimes. Ithaca: Cornell University Press, 1983. p. 93-113.

ZYSMAN, J. How Institutions Create Historically Rooted Trajectories of Growth. Industrial and Corporate Change, Oxford, v. 3, n. 1, p. 243-283, mar. 1994.

\section{Sobre os autores}

MarceloArend-marcelo.arend@ufsc.br

Departamento de Economia e Relações Internacionais, Universidade Federal de Santa Catarina, Florianópolis, SC, Brasil.

ORCID: https://orcid.org/0000-0002-5748-9690. 
Arend, Fagotti \& Moreira

Vinicius Zuniga Fagotti - viniciuszuniga@yahoo.com

Mestrando em Ciências Econômicas, Universidade de Pisa e Escola de Estudos Avançados Sant'Anna, Pisa, Itália. ORCID: https://orcid.org/0000-0001-9203-4053.

Arthur Gomes Moreira - am941@sussex.ac.uk

Doutorando em Science and Technology Policy Studies, Science Policy Research Unit - University of Sussex, Brighton, Reino Unido.

ORCID: https://orcid.org/0000-0002-0136-0855.

\section{Sobre 0 artigo}

Recebido em 01 de dezembro de 2019. Aprovado em 17 de fevereiro de 2020. 